\title{
How the poor in a developing country view business' contribution to quality-of-life 5 years after a national economic crisis
}

\author{
Mark Peterson ${ }^{\mathrm{a}, *}$, Ahmet Ekici $^{\mathrm{b}}$, David M. Hunt ${ }^{\mathrm{a}}$ \\ a University of Wyoming, College of Business, Department of Management and Marketing, Dept. 3275, 1000 E. University Ave., Laramie, WY 82071, United States \\ b Bilkent University, Faculty of Business Administration, 06800 Bilkent-Ankara, Turkey
}

\section{A R T I C L E I N F O}

Keywords:

Business' contribution to QOL

Consumer trust for market-related institutions

Consumer attitude toward marketing

Quality of life

QOL

Economic crisis

Subsistence marketplaces

\begin{abstract}
A B S T R A C T
This study proposes and tests a three-step model of business' contribution to quality of life 5 years after a devastating national economic crisis in a developing country. The model incorporates both a beneficent dimension of the marketplace (represented by consumer attitude toward marketing - CATM) and a nonmaleficent dimension (represented by consumer trust for market-related institutions - CTMRI). This study compares how the poor and the non-poor draw differently on these two dimensions in forming their perceptions about how business contributes to their quality of life. Beginning with the exogenous construct attitude toward changes in marketing practices since the last economic crisis (5 years ago), this study 1 ) proposes a causal model that introduces a first-order construct - Business' Contribution to My Quality of Life (BCM-QOL), and 2) explains how BCM-QOL serves as a mediator between marketplace perceptions of both beneficence and non-maleficence and quality of life. Results reveal differences between how the poor and the non-poor in a developing country think about the effects of market changes after an economic crisis. Consumers living below the Turkish poverty line, although not within the UN-defined ranks of the global poor (e.g., \$2 per-day earnings) tend to see their place in the market in a manner similar to subsistence consumers.

(c) 2009 Elsevier Inc. All rights reserved.
\end{abstract}

\section{Introduction}

Market-based efforts to alleviate poverty in developing economies depend on the degree to which citizens trust that such efforts will improve their quality of life (Ekici and Peterson, 2009). Telecommunications, information technology, and microfinance sectors all have played pivotal roles in providing relief to those in poverty (Petkoski et al., 2008). An important question remains, however - how do the poor perceive the positive or negative impact of these and other marketing institutions on their quality of life? Additionally, do the poor differ from the non-poor in the way they form their perceptions about business' contribution to quality of life?

A variety of research illustrates the potential negative social consequences of the actions of marketing institutions (Harris and Carman, 1983; Mittelstaedt et al., 2006). Among the poor, these negative consequences may manifest themselves as constraints on their achievement of substantive freedoms (Sen, 1999) or as negative influences on overall quality of life (Ekici and Peterson, 2009). Specifically, the poor may view the marketplace as a dominant social institution that can inhibit their quality of life, but cannot directly supply enough benefits to improve the same. For instance, subsistence consumers from South India report that uncertainty and fear of the

\footnotetext{
* Corresponding author.

E-mail addresses: markpete@uwyo.edu (M. Peterson), ekici@bilkent.edu.tr (A. Ekici), dhunt@uwyo.edu (D.M. Hunt).
}

next crisis bind them to their neighborhood stores, despite the substantial premium that such stores often charge (Viswanathan et al., 2009). This view of the market as an inherently risky domain contrasts with conceptualizations of the market as a well of opportunity (Lee and Sirgy, 2004).

Despite contrasting conceptualizations of the influence of business on quality of life, and despite the proliferation of market-related efforts to alleviate poverty, little empirical research has explored how the actions of businesses influence attitudes about business' contribution to quality of life among the poor. Specifically, research has not addressed the degree to which the poor differ from the non-poor in viewing marketplace activities of buyers, sellers, workers, and government regulators as positive or negative influences on their quality of life.

This study proposes and tests a model of business' contribution to quality of life. The model incorporates both beneficent (achieving positive outcomes) and non-maleficent (avoiding harmful outcomes) dimensions of the marketplace. This study compares how the poor and the non-poor draw differently on these two dimensions in forming their perceptions about how business contributes to their quality of life. By exploring this issue with respect to attitude toward changes in marketing practices since the last economic crisis ( 5 years ago), this study proposes a causal model that introduces a first-order construct - Business' Contribution to My Quality of Life (BCM-QOL); and explains how BCM-QOL serves as a mediator between marketplace perceptions of both beneficence and non-maleficence and quality of life. 
In Sections 2 and 3 below, this study includes a three-step model of how perceived changes in marketing practices since the last economic crisis influence perceived quality of life. The authors draw upon macromarketing research on poverty and on quality of life to advance four hypotheses regarding the three-step model, as well as whether the model might differ between the poor and non-poor. Next, the authors describe the methods and findings from an empirical study conducted among poor and non-poor consumers in Turkey 5 years after a national economic crisis. The paper concludes by discussing the interpretation of the study's findings in the context of research on subsistence marketplaces and quality of life in developing countries.

\section{Conceptual framework}

\subsection{Macromarketing issues for the poor}

In developing countries, the poor often experience marketing activities as constraining influences upon their quality of life (Ekici and Peterson, 2009). Specifically, the poor's lack of access to education, healthcare, and vocational training can influence quality of life factors such as personal health, freedom of movement, thought and emotions, control over political and material environments, and even life duration (Sen, 1999). An "...undercurrent of resignation" (Viswanathan and Rosa, 2007, pg. 8) characterizes people's thoughts in contexts where segments of the population perpetually live in poverty. That is, consumers have given up on marketers' actions significantly benefiting their lives. As such, even poor consumers who do not necessarily live in conditions of abject poverty may view business' contribution to their quality of life in terms of avoiding the oppressive aspects of the market rather than in terms of reaping the market's benefits. The fact that these attitudes are negative in valence, does not mean that changes to marketing policies and institutions cannot positively impact quality of life for poor consumers. Consumers may perceive changes as contributing to their overall quality of life. However, rather than viewing the contribution to quality of life in terms of reaping the benefits of market changes, poor consumers may view business' contribution to quality of life in terms of avoiding the harmful aspects of market changes.

\subsubsection{Attitude toward the five-year change in marketing}

Researchers consider evaluation to constitute the core of a person's attitude (Ajzen, 2008). This study aims to better understand consumers' evaluations of marketing management practices aimed at recovering from an economic crisis. Attitudes toward marketing management practices have four key dimensions - product quality, pricing, advertising, and retailing conditions. As such, a comprehensive view of changes in marketing should consider at least these four factors in their shaping attitudes toward business's contribution to quality of life. Experience and knowledge are two important antecedents of trust (Doney and Cannon, 1997) and attitudes (Eagly and Chaiken, 1993). Therefore, this study proposes that evaluations of changes in marketing practice since the last economic crisis will directly and positively influence consumers' current trust for market-related institutions and current attitudes toward practices in the marketplace.

\subsubsection{Trust for market-related institutions}

This study follows research regarding Consumer Trust for MarketRelated Institutions (CTMRI) and Quality of Life (QOL) (Ekici and Peterson, 2009). Trust is a crucial element in dealing with an uncertain and uncontrollable future. Institutional trust includes the public trust consumers direct at institutions (the specific structural arrangement within which actions and interactions take place (Sztompka, 1999)). With institutional trust, citizens consider the extent to which they trust the institution (the government or business) to fulfill its role in a satisfying manner. For example, a lack of trust in government regulators to ensure product safety may lead individuals to rely on non- governmental sources for information about products (such as the Consumers Union in the US) or to avoid consumption of the product altogether (as in the case of drops in demand for beef due to mad cow disease concerns). In this way, one can see that trust for institutions depends on the perceived performance of such institutions. In addition to trust of government regulators, consumers direct institutional trust at market-related institutions such as consumer groups, manufacturers and retailers, and the media (Ekici and Peterson, 2009). In this study, researchers examine institutional-level trust for marketing management practices. This approach illuminates the trust resulting from the perceived performance of these aggregate institutions, which function together as part of society's market ecosystem. Therefore, this study proposes that perceptions of changes in marketing during the last 5 years will positively associate with consumers' trust for marketrelated institutions.

\subsubsection{Consumer attitude toward marketing}

Researchers have sought understanding of the effectiveness of businesses in a society's Aggregate Marketing System (AGMS) (Wilkie, 2006). While government and non-profits also participate in AGMS, in many societies businesses that serve consumers represent a majority of AGMS' activities. Consumers' sentiments toward key activities of marketing practice indicate the marketing system's performance in delivering well-being to consumers (Gaski and Etzel, 1986; Varadarajan and Thirunarayana, 1990). Key business activities that shape market attitudes include perceived value and truthfulness of advertising, the perceived value of retail experiences, perceived fairness in pricing, and satisfaction with the provision of goods and services (Peterson and Ekici, 2007). Based on the causes and influences of environmental change on the marketing system (Grossbart et al., 2001, 2002), researchers of this study expect that attitude toward five-year changes in marketing will directly influence consumer attitude toward marketing (CATM).

\subsection{Non-maleficent and beneficent aspects of markets}

Researchers view markets as social arenas where firms, their suppliers, customers, workers, and governments interact (Fligstein and Dauter, 2007). Markets imply social spaces where repeated exchanges occur between buyers and sellers under a set of formal and informal rules governing relations between competitors, suppliers, and customers. These marketplaces depend upon governments, laws, and larger cultural understandings supporting market activity. A sociology of markets suggests that market actors develop social structures (such as norms, laws and enforcement agencies) to address the problems they encounter in exchange, competition, and production.

This macromarketing view of the marketplace acknowledges a well-developed infrastructure that contributes to the ongoing success of market transactions in modern economies. However, imperfect information among parties involved in market transactions (Nason, 1989) can lead to negative consequences for people directly involved in exchange (Harris and Carman, 1983) and for those not directly involved (Mittelstaedt et al., 2006). Unlike market ideology viewing free markets as simple and alluring, this view of market transactions acknowledges that not all consequences of market transactions are positive. This infrastructure includes regulations, enforcement agencies, industry associations, courts, consumer groups, and media. Such a macromarketing view implies that markets offer benefits, as well as problems to participants. In other words, markets have dimensions of beneficence and maleficence.

In offering a positive lens to what markets offer society, Lee and Sirgy (2004) conceptualized QOL Marketing as having two dimensions: 1) marketing beneficence, and 2) marketing non-maleficence. Marketing that enhances QOL (for society, communities and individuals), in other words, has a benefits dimension and an avoidance of harm dimension. For example, the benefits of using a personal 
computer include the creation of electronic documents, and all the communication abilities offered by internet connectivity. However, policy should seek to eliminate or minimize hazards (such as exploding cathode ray tubes or consumer exposure to toxic components) of using personal computers. Additionally, policy should aim to avoid societal costs associated with detoxifying landfills where many computers are placed after their usefulness has expired.

\subsection{Quality of life}

Quality of life - or subjective well-being - refers to affective experiences and cognitive judgments about one's life (Larsen and Eid, 2008). Quality of life is the product of an overall appraisal of life that includes both good and bad experiences. Based on bottom-up spillover theory and empirical evidence, Lee et al. (2002) hypothesized that consumer well being (CWB) predicts life satisfaction as reflected by QOL. These researchers found empirical evidence supporting CWB's direct influence on overall life satisfaction - a key measure of quality of life (QOL). In a similar vein, this study proposes that attitudes about business' contribution to quality of life will positively associate with attitudes toward overall quality of life.

\subsection{Comparing attitudes of the poor to attitudes of the non-poor}

Previous quality of life research among the poor focused on how relationships between constructs representing CTMRI, distrust for individuals, and subjective quality of life (QOL) might differ across groups separated by the poverty line in a developing country (Ekici and Peterson, 2009). Trust positively influenced quality of life perceptions among the poor. However, the non-poor did not exhibit that same influence. In other words, living below the poverty line with low trust in marketing-related institutions seems to lead to lower perceptions of business' contribution to quality of life. In contrast, living above the poverty line seems to lead to higher perceptions of business' contribution to quality of life. Further, recent research about vulnerable consumers, such as those facing financial constraints (Baker et al., 2006), suggests their perceptions about the marketplace and their sentiments toward marketing practices are likely distinct from consumers who do not experience such vulnerability. As such, researchers of this study expect that the poor will differ from the nonpoor in the formation of their attitudes toward business' contribution to quality of life.

\section{Research issues and hypotheses}

Previous quality of life studies have conceptualized constructs such as consumer trust for marketing related institutions (CTMRI) and consumer attitude toward marketing (CATM) as higher-order constructs related to QOL in a nomological sense. By incorporating only one or the other of these constructs, previous studies have emphasized either the beneficent or the non-maleficent aspects of the marketplace. However, previous research stopped short of simultaneously investigating the effect of consumer attitudes toward these two aspects of the marketplace (beneficent and non-maleficent dimensions) on quality of life perceptions. Moreover, previous studies limited themselves to finding a correlation between one of these two constructs and overall life satisfaction (QOL). By emphasizing only a single dimension, previous research has over-looked how these dimensions may operate differently on QOL perceptions between poor and non-poor in developing countries.

This study aims to better understand how both beneficent and nonmaleficent constructs behave in the same model. Accordingly, researchers of this study propose that non-maleficent perceptions regarding trust in market-related institutions (CTMRI) and attitudes regarding market beneficence (CATM) mediate the relationship between perceptions about changes in marketing practices in the last 5 years and perceptions of business' contribution to one's quality of life.

Fig. 1 depicts a proposed three-step flow model. Developing country consumers' attitude toward the five-year change in marketing represents the impact of such changes in the mind of the consumer. Anchored in reflections about conditions 5 years prior, the attitude toward the five-year change in marketing construct is exogenous in the model. In step one, Attitude toward the Five-Year Change in Marketing directly influences current perceptions about market non-maleficence (CTMRI), as well as beneficence (CATM). In step two, CTMRI and CATM influence consumers' ratings of how much business contributes to their own quality of life (BCM-QOL). In step three, BCM-QOL directly influences overall life satisfaction (QOL) (Lee et al., 2002).

In developing this model, researchers aim to better understand how consumers in a developing country perceive the contributions of business institutions to their overall life satisfaction. Additionally, this study seeks to better understand how the poor differ from the nonpoor in the formation of QOL perceptions. More specifically, the theoretical model illustrates a proposed flow process whereby attitudes about changes in marketing practices influence both perceptions of beneficent and non-maleficent aspects of the marketplace. Subsequently, these perceptions about market non-maleficence and

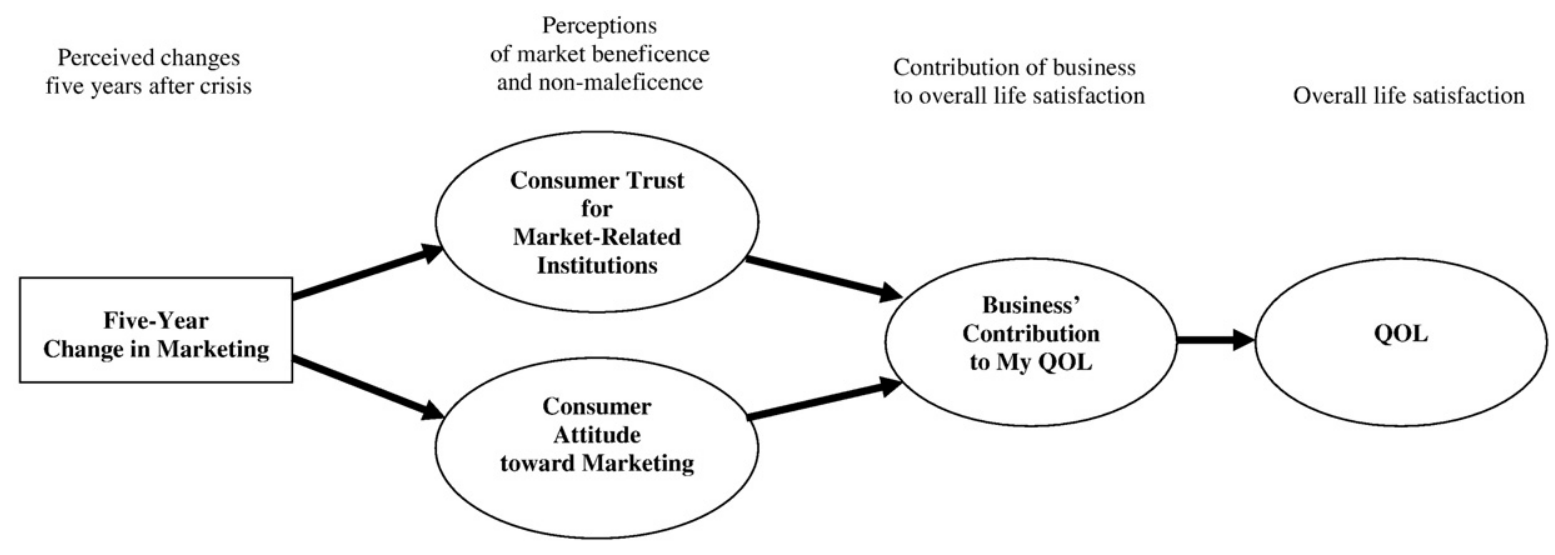

STEP 1

STEP 2

STEP 3

Fig. 1. proposed three-step model of five-year change in marketing's influence on QOL. 
beneficence influence ratings of QOL. Based on the discussion of conceptual model in Section 2, this study includes the following hypotheses:

H1. Attitude toward the five-year change in marketing will positively influence

H1a. trust for market-related institutions (CTMRI) and

H1b. attitude toward current marketing practices (CATM).

H2a. Consumer trust for market-related institutions (CTMRI) will positively influence one's judgment about what business contributes to one's own QOL (BCM-QOL).

H2b. Consumer attitude toward marketing (CATM) will positively influence one's judgment about what business contributes to one's own QOL (BCM-QOL).

H3. Judgment about what business contributes to one's own QOL (BCM-QOL) will positively influence one's overall life satisfaction (QOL).

H4. The pattern of relationships between attitude toward 5 yearchange in marketing, CTMRI, CATM, BCM-QOL and QOL will differ for those living below the poverty line when compared with those living above the poverty line.

\section{The study}

\subsection{Research setting}

The developing country of Turkey serves as the context for the empirical study. During the last 40 years, Turkish consumers have experienced substantial economic growth, but also acute turns in the business cycle, hyperinflation, price controls, rapid currency devaluation, natural disasters (earthquakes), civil unrest, government corruption, military-run governments, and both domestic and internationally-sponsored terrorism. Life in Turkey shares many features with life in other developing countries.

In 2001, the Republic of Turkey encountered the most severe economic crisis (referred to as "Black Wednesday" by the public) in the country's history (Zabci, 2006). In a week's time, the Turkish currency, the Lira, was devalued by approximately 40\% making repayment of debts in foreign currency difficult for banks and businesses (Leicht, 2001). Losses at the state banks ran into billions of dollars, and consumed half the expected tax receipts for 2001. Thousands of businesses failed and hundreds of thousands of Turkish workers lost their jobs (Zabci, 2006). The Turkish government eliminated over 400,000 jobs in the public sector through layoffs and offers of early retirement. Many unprofitable banks closed. By December 2002, unemployment had risen to an all-time high of $11.4 \%$. The unemployment rate reached almost $12 \%$ and real wages dropped more than 20\%. Through 2008, neither the unemployment situation nor real wages had recovered (Yeldan, 2008).

The economic crisis negatively affected all sectors of Turkish society - but to different degrees. More than any previous economic crisis, the 2001 economic crisis worsened income disparities between the poor and non-poor. In general, the economic crisis hit poor consumers disproportionately harder.

The economy for the laboring class never really recovered after the 2001 crisis. Those with informal employment (lacking regular health insurance), migrants who could not settle around the neighborhoods of their "hemşeri" (fellows from their hometown), and people who could not receive support from their families and other social networks continued to suffer the effects from the economic crisis (Bugra and Keyder, 2003). Even though Turkey provides citizens free public education, various hidden costs (i.e., uniforms and other clothes, books and notebooks, and contributions requested by school administrators) have made attending school unaffordable for many of the poor in Turkey during and after the crisis. This example illustrates how debilitating market conditions can deprive people of substantive freedoms such as the ability to imagine and to think critically (Sen, 1999).

Güvenç and Şenyapılı (2003) investigated the social consequences of the 2001 crisis among 783 households in Istanbul. The study included households from three segments: 1) irregular/non-unionized labor; 2) regular/unionized labor; and 3) white collar service employees. Lower education and low incomes characterize the first two segments whereas higher education and high incomes characterize the third segment. The study revealed that even though all segments survived the crisis, low-income segments were more drastically affected than non-poor segments. While all segments in the study had to reduce their food (kitchen) expenditures, for example, food choices of the poor, when compared to those of the more affluent, service employees were focused on inferior quality food items during the crisis and afterwards.

The crisis most drastically impacted the area of health. Since the beginning of the crisis, only those with some modicum of health insurance could receive health services when needed. More than half of the poor studied could not afford to receive any treatment when ill. Poor families, compared to non-poor families, indicated a more negative outlook about the economy. In contrast, white-collar service employees were generally optimistic about the future. In addition to economic difficulties, poorer households indicated worsened psychological health.

While the household income of the white collar service employees remained relatively the same, the household income of other segments decreased. Moreover, as compared to lower-income segments, most of the white-collar service employees retained their jobs after the crisis. All family segments studied borrowed more money (through bank loan or credit cards), however, more than half of those borrowers belonged to the low-income segment.

About one third of the people (head of households) studied had either lost or changed jobs after February 2001. Seventy-five percent of poor households, compared to only $25 \%$ of white-collar households lost or changed their jobs as a result of the crisis. Among the poor, $70 \%$ of those who lost jobs were also the head of the household (i.e. the wage earner in the household). In contrast, only $30 \%$ of the whitecollar employees who lost jobs were the primary wage earners in the household. Because "white collar" households have relatively higher levels of education, other family members (other than the head of the household) could still have a job and earn money for their families. As a result, even though the government statistics indicate that unemployment rose to a high of $11.4 \%$ in December 2002, the crisis more drastically impacted the poor (Güvenç and Şenyapılı, 2003).

When natural or man-made disasters disrupt consumers' lives, the market's influences upon quality of life are set in high relief (Baker et al., 2007; Becker 1997). That is, Turkish citizens experienced the responses of market-related institutions to an economic crisis in rich ways. As such, they are in a position to assess the performance of the society's market-related institutions in the 5 years following an economic crisis. Thus, the transitional stage of Turkey's economic recovery, provides a good context to study institutional trust, attitude toward marketing and quality-of-life.

\subsection{Research design}

This study included a survey of a broad cross-section of Turkish consumers 21 years of age and older following the protocols used by Peterson and Ekici (2007) in their study of developing country consumers. Seven-point Likert-type scales were used ( $1=$ strongly disagree/7 = strongly agree). Data analysis was performed on a set of items representing one item parcel (attitude toward five-year change in marketing), two second-order constructs (CTMRI and CATM), as well as two first-order constructs (BCM-QOL and QOL). Confirmatory factor analysis using structural equation modeling was performed prior to assessing the focal structural model of the study. 
This study used the survey administration procedures detailed in Ekici and Peterson (2009) that included parallel translation into Turkish (from English) by a professional translation company in Turkey using both native English and native Turkish speakers (Douglas and Craig 2006). The survey was administered at several locations in four cities of Turkey. The survey included data collected in the three largest metropolitan cities in Turkey and in a town of about 90,000 residents in the Black Sea region. Quota sampling based on age was used. A small cash incentive was given to those who completed the survey. In order to obtain a suitable number of non-poor consumers for comparison with the poor, a second data collection effort using judgment sampling was undertaken. These steps resulted in a sample that was generally representative of the Turkish population.

\subsection{Operationalization of constructs}

In fielding a large-scale survey of Turkish consumers, this study adopted an expectancy-value approach to the measurement of attitude toward the five-year change in marketing (Fishbein and Ajzen, 1975). Here, the degree of perceived change in each of the four marketing management dimensions was sought from consumers. This was then multiplied by the importance of this dimension to the consumer. Finally, a summative scale was created by adding the products of multiplying the perceived change of each dimension by the importance of each dimension. In this way, the impact of the perceived changes in marketing could be assessed as an attitude toward these changes. The measure served as an exogenous variable reflecting how such changes have influenced current levels of trust for market-related institutions (Ekici and Peterson, 2009), attitude toward marketing (Peterson and Ekici, 2007), and downstream QOL constructs for consumers in developing countries. Anchoring the model in attitude toward a historical event enhances the study's ability to draw inferences about causality (Malhotra, 2009).

Measures used in Gaski and Etzel's (1986) Index of Consumer Sentiments toward Marketing (ICSM) were enhanced and refined in previous studies featuring Turkish consumers (Peterson and Ekici, 2007). Using a confirmatory-factor-analysis approach, these measures were used to derive a second-order factor representing CATM. A moderate positive relationship between CATM and QOL was found (Pearson's correlation coefficient $=.47$ ).

This study focused on businesses, research and development companies, and research companies that were salient to consumers. Accordingly, consumers were asked how 1) local businesses, 2) national businesses, 3) multinational businesses, 4) new product

Table 1

Descriptive statistics for construct items $(N=264)$.

\begin{tabular}{|c|c|c|c|c|}
\hline & Mean & S.D. & Skewness & Kurtosis \\
\hline Five year change in mktg & 52.86 & 13.99 & 0.09 & -0.04 \\
\hline \multicolumn{5}{|l|}{ CATM - business provision } \\
\hline q2.6 - Businesses provide the shopping experiences I want & 3.02 & 1.07 & -0.12 & -0.43 \\
\hline q2.7 - Businesses provide the goods I want & 3.14 & 1.03 & -0.33 & -0.39 \\
\hline q2.8 - Businesses provide the services I want & 3.03 & 0.99 & -0.08 & -0.19 \\
\hline \multicolumn{5}{|l|}{ CATM - Positive advertising } \\
\hline q3.6 - Most advertising is not annoying & 2.79 & 1.37 & 0.13 & 1.16 \\
\hline q3.7 - Most advertising makes true claims & 2.3 & 1.18 & 0.5 & 0.78 \\
\hline q3.10 - Most advertising is intended to inform rather than deceive & 2.93 & 1.22 & 0.55 & 0.83 \\
\hline \multicolumn{5}{|l|}{ CATM - Fair pricing } \\
\hline q3.13 - Most prices are reasonable given the high cost of doing business & 2.44 & 1 & 0.42 & -0.19 \\
\hline q3.14 - Most prices are fair & 2.37 & 0.97 & 0.54 & 0.11 \\
\hline q3.15 - In general, I am satisfied with the prices I pay & 2.37 & 0.97 & 0.41 & -0.15 \\
\hline \multicolumn{5}{|l|}{ CATM - Retail service } \\
\hline q3.16 - Most retail stores serve their customers well & 3.06 & 1.01 & -0.14 & -0.15 \\
\hline q3.18 - I find most retail salespeople to be very helpful & 2.57 & 0.98 & 0.24 & -0.17 \\
\hline q3.20 - Most retailers provide adequate service & 2.84 & 0.98 & -0.06 & -0.24 \\
\hline \multicolumn{5}{|l|}{ CTMRI - Trust for govt. regulation } \\
\hline q7.5 - I trust the government to retain its integrity when lobbied by businesses & 2.29 & 1.18 & 0.68 & -0.31 \\
\hline q7.6 - I trust gov't to protect consumers & 2.33 & 1.16 & 0.61 & -0.34 \\
\hline q7.7 - I trust gov't to appropriately regulate businesses & 2.25 & 1.11 & 0.66 & -0.19 \\
\hline q7.8 - I trust gov't to do research that will ensure public safety & 2.38 & 1.18 & 0.6 & -0.5 \\
\hline \multicolumn{5}{|l|}{ CTMRI - Trust for consumer gps. } \\
\hline q7.11 - I trust consumer groups to offer credible information & 3.19 & 1.03 & -0.22 & -0.33 \\
\hline q7.12 - I trust consumer groups to educate the public & 3.06 & 1.03 & -0.14 & -0.38 \\
\hline q7.13 - I trust consumer groups to remain independent of business & 2.93 & 1.05 & -0.08 & -0.43 \\
\hline \multicolumn{5}{|l|}{ CTMRI - Trust for mfrs. and business } \\
\hline q7.1 - I trust manufacturers to ensure product safety & 2.57 & 0.99 & 0.29 & 0.03 \\
\hline q7.2 - I trust manufacturers to package products appropriately. & 2.73 & 1.01 & 0.1 & -0.37 \\
\hline q7.3 - I trust businesses to abide by regulations protecting consumers & 2.41 & 1.04 & 0.46 & -0.23 \\
\hline q7.4 - I trust businesses to efficiently provide what consumers want & 2.56 & 1.00 & 0.16 & -0.39 \\
\hline \multicolumn{5}{|l|}{ CTMRI - Trust for news/entertainment media } \\
\hline q7.15 - I trust the news media to serve as a watchdog against wrong-doing to consumers & 2.46 & 1.21 & 0.39 & -0.91 \\
\hline q7.16 - I trust the entertainment media to create enough entertainments safe for all consumers & 2.13 & 1.08 & 0.59 & -0.51 \\
\hline \multicolumn{5}{|l|}{ Business' Contribution to My QOL } \\
\hline q6.2 - New product developers' contribution to MY QOL & 4 & 1.03 & -0.99 & 0.61 \\
\hline q6.3 - MNEs' contributions to MY QOL & 3.42 & 1.12 & -0.41 & -0.46 \\
\hline q6.4 - National businesses' contributions to MY QOL & 3.64 & 1.06 & -0.61 & 0.02 \\
\hline q6.5 - Local businesses' contributions to MY QOL & 3.56 & 1.06 & -0.41 & -0.29 \\
\hline q6.6 - Marketing research companies' contributions to MY QOL & 3.21 & 1.11 & -0.05 & -0.7 \\
\hline \multicolumn{5}{|l|}{ QOL } \\
\hline q2.1 - My life is close to my ideal & 3.02 & 1.09 & -0.17 & -0.51 \\
\hline q2.2-Conditions of my life are excellent & 3.08 & 1.07 & -0.21 & -0.4 \\
\hline q2.3 - I am satisfied with my life & 3.52 & 1.15 & -0.54 & -0.36 \\
\hline q2.4 - I have gotten the important things I want in life & 3.1 & 1.12 & -0.25 & -0.58 \\
\hline q2.5 - If I could live my life over, I would change almost nothing & 2.73 & 1.28 & 0.14 & -1.09 \\
\hline
\end{tabular}


developers, and 5) marketing research companies contribute to their quality of life. These dimensions are captured in the measure for perceptions of business' contribution to quality-of-life (BCM-QOL).

Lee et al. (2002) showed empirical support for life satisfaction being an important consequence of what consumers gain from markets. Here, life satisfaction was represented by a single-item measure. Numerous studies in international research have successfully used multi-item measures of subjective quality-of-life. For example, psychological researchers have widely employed Diener et al.'s (1985) Satisfaction with Life Scale (SWLS) with consistent reliability and validity (Burroughs and Rindfleisch, 2002) in studies conducted in dozens of countries (Diener et al., 1999). Norms for a seven-point SWLS have ranged from 4.0 in China to 6.23 in Australia. Turkey and the U.S. place in the middle of countries with 5.29 and 5.77, respectively. The SWLS is a five-item measure intended to assess cognitive aspects of well-being and includes such items as "The conditions of my life are excellent.", and "I am satisfied with my life." Importantly for this study, previous research investigating CTMRI (Ekici and Peterson, 2009) and CATM (Peterson and Ekici, 2007) successfully employed the SWLS.

\subsection{Selection of poverty line}

The poverty line in Turkey at the time of the study's design was about 1867 TL per month for a four-member family according to Türkİs, the leading confederation of labor unions (New Anatolian, 2006). White (2008) criticizes unions in Turkey for calculating poverty lines that are too high. Because of this criticism, this study adjusted the poverty line for Türk-İs downward to $1500 \mathrm{TL}$ per month for each household. By comparison, the Türk-İş hunger line for 2006 was 573 TL per month for a four-member household. Setting the poverty line too low is undesirable (du Toit, 2005). Accordingly, researchers in this study desired to select a poverty line that was too high rather than too low, so this study used the revised Türk-İs poverty line. Using the revised Türk-İs poverty line, avoids the potential problem of having a conservative threshold that is politically palatable but that disguises widespread poverty existing above the line.

\section{Results}

\subsection{Initial analyses}

The survey procedures resulted in 318 usable surveys. Males comprised $58 \%$ of respondents. Fifty-one percent of respondents were married and $48 \%$ of the respondents were in the $21-30$ age-group. The modal value for education level was "high school graduate". Seventyseven percent of respondents reported working outside the home on a regular basis. The modal value for monthly household income was 501-1500 Turkish Lira or TL (approximately \$300-\$1,000). Fifty-nine percent of the sample was at or below the 1500 TL threshold used in this study to more conservatively identify the poverty line.

Common factor analysis was conducted with a pooled set of 36 items, which included all the items measuring 1) attitude toward the five-year change in marketing, 2) the four dimensions of CTMRI, as well as the four dimensions of CATM, 3) BCM-QOL and QOL (Gerbing and Anderson, 1988). Table 1 illustrates the items used in the study. Maximum likelihood extraction identified the multi-item constructs in the model, and assessed both the convergent, and discriminant validity of the constructs in the model in the manner recommended by Hair et al. (1991). This study found evidence supporting both convergent and discriminant validity for all constructs.

Prior to the next round of modeling, sample balancing made the two groups equal in size with 132 respondents each. One hundred thirty two cases in the poor group were randomly selected to match the 132 comprising the non-poor group. Subsequently, a comparison of models on both sides of the poverty line assessed differences in the pattern of relationships across the two groups.

Table 2 presents descriptive statistics for each group (poor and non-poor). The descriptive analysis confirms expectations that consumers living below the poverty line are younger and are more likely to be single. Notably, those living below the poverty line reported a mean score on all the subjective QOL items lower than the mean score of those living above the poverty line. The poor posted means ranging from 2.44 (standard deviation of 1.24) to 3.35 (standard deviation of 1.19). By comparison, the non-poor posted means ranging from 3.02 (standard deviation of 1.24) to 3.73 (standard deviation of 0.97). This is consistent with literature noting the moderating effect of income on QOL (Sirgy, 2001).

\subsection{Modeling}

Fig. 2 depicts modeling for the entire sample. Covariance analysis using AMOS 7 was used to evaluate the factor structure of the 36 items (Bollen, 1989) in a confirmatory factor analysis with the initial group of 318 , and then to test the proposed three-step model. The model posted a chi-square value of 903.6 with $581 \mathrm{df}$. Comparative fit indicators suggested a good fit $(\mathrm{CFI}=.94$; RMSEA $=.04$ ) (Bentler, 1990). As such, fit indices and the confirmatory factor analysis suggest a high degree of model fit. Importantly, because all the structural coefficients in the model were statistically significant at $p=.05$, Hypotheses $1-3$ were supported.

Table 2

Comparison of factor score means across the poverty line.

\begin{tabular}{|c|c|c|c|c|c|c|c|c|c|c|c|}
\hline \multicolumn{2}{|l|}{ Monthly household income } & \multicolumn{2}{|c|}{ Five year change in mktg } & \multicolumn{2}{|c|}{ CATM - business provision } & \multicolumn{2}{|c|}{ CATM - price } & \multicolumn{2}{|c|}{ CATM positive advertising } & \multicolumn{2}{|c|}{ CATM - retail service } \\
\hline HH monthly income & Mean & 51.67 & & 14.93 & & 12 & & 10.22 & & 14.45 & \\
\hline less than or equal to $1500 \mathrm{TL}$ & S.D. & 14.64 & & 5.55 & & & 17 & 5.92 & & 5.38 & \\
\hline HH monthly income & Mean & 54.05 & & 15.38 & & & & 10.27 & & 15.60 & \\
\hline greater than $1500 \mathrm{TL}$ & S.D. & 13.26 & & 4.82 & & & 76 & 5.49 & & 4.56 & \\
\hline $\begin{array}{l}\text { Difference between gp. means } \\
\text { (below group minus above group) }\end{array}$ & & -2.38 & & -0.45 & & & & -0.04 & & $-1.15^{*}$ & \\
\hline Monthly household income & & $\begin{array}{l}\text { CTMRI }- \text { trust } \\
\text { govt regulation }\end{array}$ & $\begin{array}{l}\text { CTM } \\
\text { cons }\end{array}$ & $\begin{array}{l}\text { RI - trust } \\
\text { umer gps }\end{array}$ & $\begin{array}{l}\text { CTMRI - trust } \mathrm{m} \\
\text { and businesses }\end{array}$ & & $\begin{array}{l}\text { CTMRI - } \\
\text { entertain }\end{array}$ & $\begin{array}{l}\text { trust news and } \\
\text { ment media }\end{array}$ & $\begin{array}{l}\text { Business' } \\
\text { to My QO }\end{array}$ & contribution & QOL \\
\hline $\begin{array}{l}\text { HH monthly income } \\
\text { less than or equal to } 1500 \mathrm{TL}\end{array}$ & $\begin{array}{l}\text { Mean } \\
\text { S.D. }\end{array}$ & 0.05 & -0 & & -0.03 & & 2.40 & & -0.02 & & -0.25 \\
\hline & & 1.02 & 0 . & & 0.99 & & 1.08 & & 1.01 & & 0.96 \\
\hline $\begin{array}{l}\text { HH monthly income } \\
\text { greater than } 1500 \mathrm{TL}\end{array}$ & $\begin{array}{l}\text { Mean } \\
\text { S.D. }\end{array}$ & -0.10 & 0 . & & 0.01 & & 2.18 & & 0.02 & & 0.25 \\
\hline & & 0.86 & 0 . & & 0.84 & & 0.93 & & 0.85 & & 0.83 \\
\hline $\begin{array}{l}\text { Difference between gp. means } \\
\text { (below group minus above group) }\end{array}$ & & 0.15 & -0 & & -0.05 & & $0.22^{*}$ & & -0.05 & & $-0.51^{*}$ \\
\hline
\end{tabular}

\footnotetext{
$*$ Difference sig. at $p=.05$.
} 


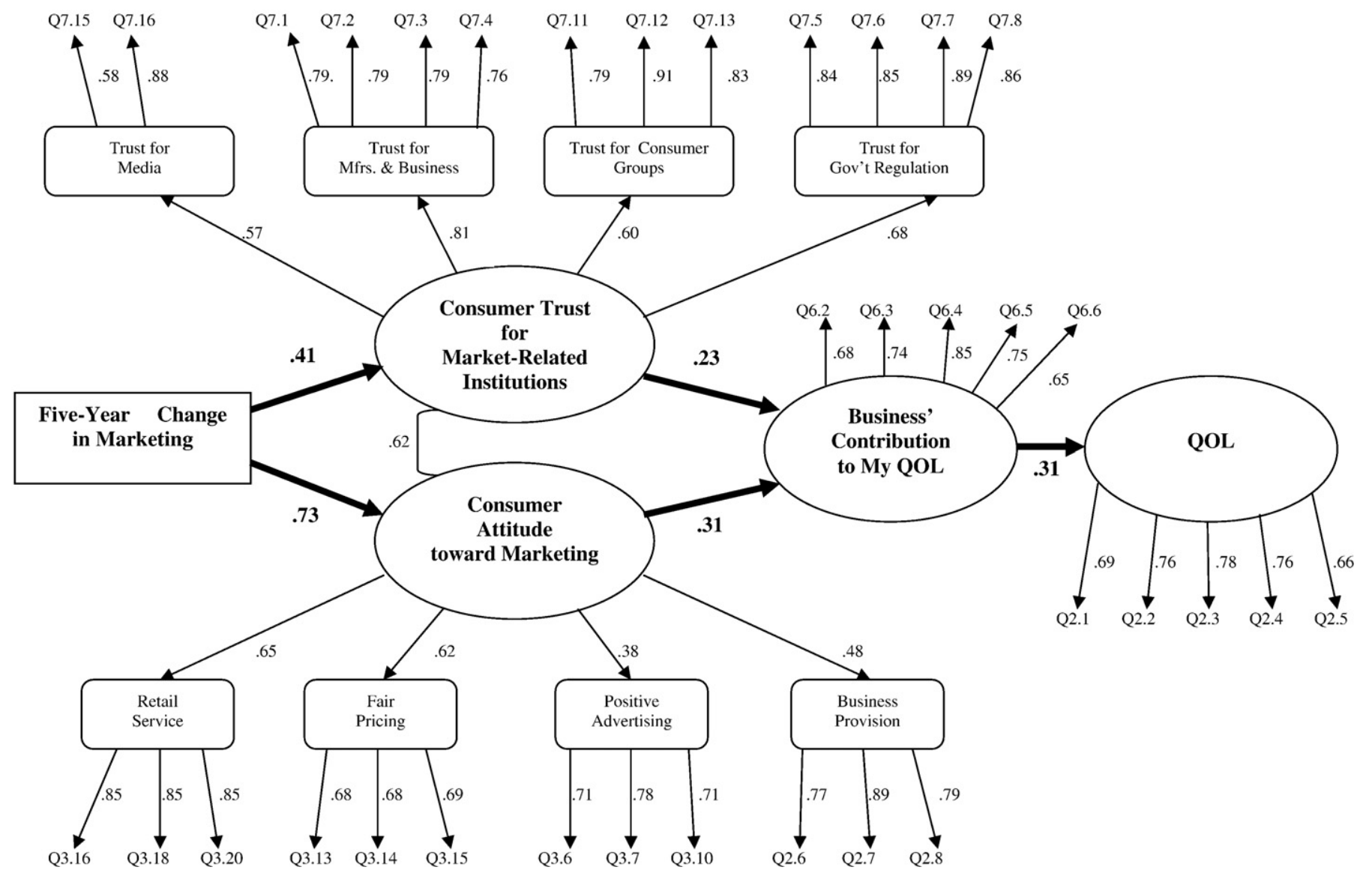

Fig. 2. Modeling results for total sample $(n=318)$.

The final model for the group below the poverty line posted a chisquare value of 868.8 with $581 \mathrm{df}$. Comparative fit indicators suggested an acceptable fit for the model (CFI $=.89$; RMSEA $=.06$ ). The final model for the group above the poverty line posted a chisquare value of 811.4 with $581 \mathrm{df}$. Comparative fit indicators suggested a good fit for the model (CFI =.90; RMSEA $=.06$ ) (Bentler, 1990). Figs. 3 and 4 depict the modeling results.

In order to address hypothesis 4 , the study needed to compare models for the poor group and the non-poor. Notably, a comparison of the model results for poor (Fig. 3) and the model results for non-poor (Fig. 4) revealed that the mediating role for BCM-QOL between CTMRI and QOL was statistically significant at $p=.05$ in the group below the poverty line - but was not significant in the group above the poverty line. (The standardized path coefficient between CTMRI and BCM-QOL was .55 for the group below the poverty line and -.06 for the group above the poverty line.) Conversely, the mediating role for BCM-QOL between CATM and QOL was statistically significant at $p=.05$ in the group above the poverty line - but was not in the group below the poverty line. (The standardized path coefficient between CATM and BCM-QOL was .66 for the group below the poverty line and -.01 for the group above the poverty line.) All the other loadings were statistically significant and generally similar across the two models.

In the subsequent multisample nested-model testing, this study first measured a baseline model in which all coefficients were unconstrained across the two sample groups (Chi-square with $1680.26 d f=1162)$. Then a nested model was tested where the standardized path coefficients between CTMRI and BCM-QOL, and CATM and BCM-QOL coefficients were constrained to be equal (Chisquare with $1686.84 d f=1164$ ). The likelihood ratio (chi-square difference test) for comparing the nested model with the baseline had $2 d f$ and was 6.58. This exceeded the criterion value of 5.99 for such a test with $2 \mathrm{df}$. When less constrained, results also exceeded the criterion value, confirming that both linkages are different across the two groups. The results suggest that one can be 95\% confident that these two linkages (1) the CTMRI and BCM-QOL linkage, and 2) the CATM and BCM-QOL linkage) differ across the models.

\subsection{Support for hypotheses}

The results from testing of the proposed three-step model in the overall sample as depicted in Fig. 2 supported hypotheses 1-3. In the first step of the model, the improvements in marketing over the last five years contributed directly to trust for market-related institutions (H1a), and one's current attitude toward marketing (H1b). Here, attitude toward the five-year change in marketing posted a positive and moderately-sized influence on CTMRI (standardized path coefficient of .41) and a positive and large-sized influence on CATM (standardized path coefficient of .73). In the next step of the model, trust (H2a) and attitude toward the market (H2b) influenced one's view about what business contributes to QOL. Here, CTMRI and CATM had positive and moderately-sized influences on BCM-QOL (standardized path coefficients of .23 and .31 , respectively). In the third and final step of the model, what businesses contribute to one's own QOL influenced overall life satisfaction (QOL) (H3). Here, BCM-QOL positively influenced one's overall life satisfaction (QOL) (standardized path coefficient of .31). In sum, the comparative fit indices of the three-step model along with the standardized path coefficients of the model provide compelling support for hypotheses one through three.

Hypotheses 4 addresses potential differences between how the poor and the non-poor in a developing country think about the effects of market changes since the last economic crisis. The results suggest that steps 1 and 3 in the three-step model are generally the same. However, the relationships comprising step 2 in the model between CTMRI and BCM-QOL and between CATM and BCM-QOL differ. Here, 


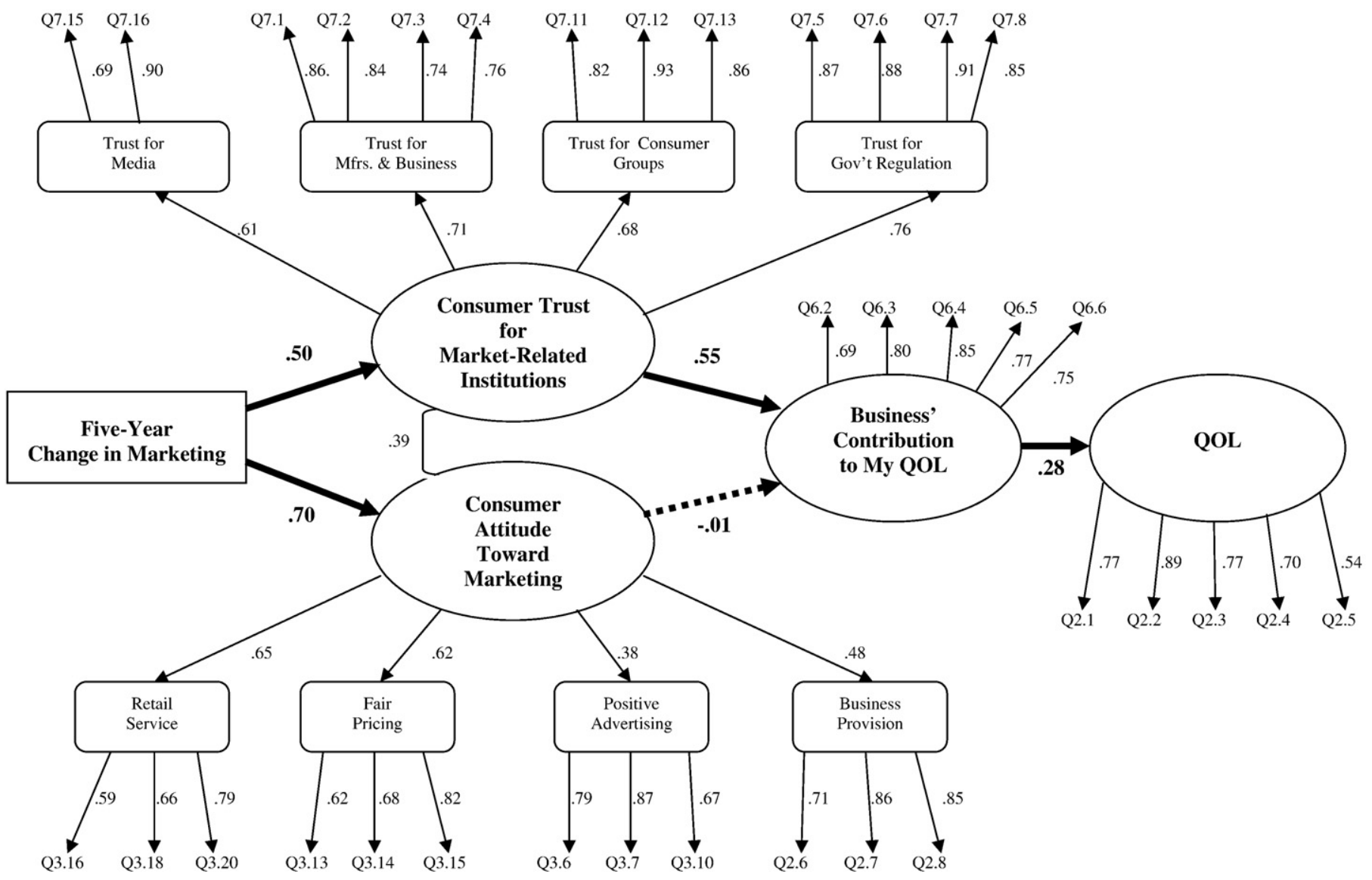

Fig. 3. Modeling results for poor - below the poverty line $(n=132)$.

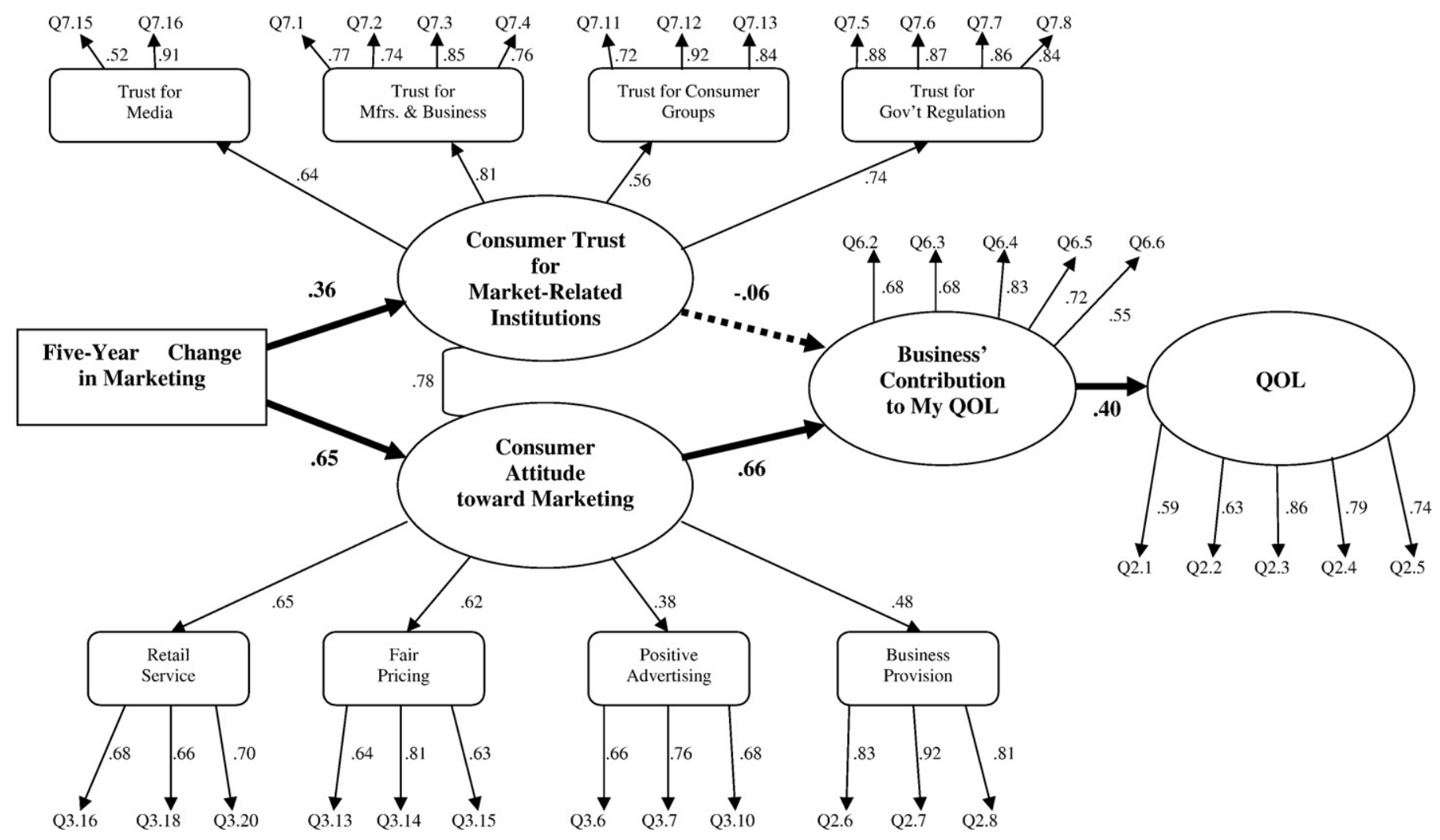

Fig. 4. Modeling results for non-poor - above the poverty line $(n=132)$. 
the poor have a positive and statistically significant relationship at the .05 level between CTMRI and BCM-QOL, but have no such relationship between CATM and BCM-QOL. In other words, trust for market-related institutions (and not one's attitude toward marketing) mediates the relationship between attitude toward five-year change in marketing and judgments about business' contributions to one's own QOL. By comparison, the non-poor emphasize attitude toward marketing (and not trust for market-related institutions) as a mediator of attitude toward five-year change in marketing and judgments about business' contributions to one's own QOL.

\section{Discussion}

\subsection{Comparing the poor and the non-poor}

Consumer Trust for Market-Related Institutions and Consumer Attitude toward Marketing serve different roles for poor compared to non-poor consumers when they consider the effects of changes in marketing since the last economic crisis. CTMRI serves as a mediating construct for the poor, but does not for the non-poor. By comparison, CATM serves as a mediating construct for the non-poor, but does not for the poor.

Results suggest that, in a developing country, trust in marketrelated institutions positively impacts poor consumers' quality-of-life perceptions. Researchers can understand the role for trust of marketrelated institutions among the poor as a "simplifying strategy that enables individuals to adapt in a complex social environment, and thereby benefit from increased opportunities" (Earle and Cvetkovich, 1995, p.38). In a complex and uncertain environment with an uncontrollable future, trusting market-related institutions becomes a crucial life-simplifying strategy for consumers. Trusting gives individuals the opportunity to trade an uncontrollable future for a more predictable one. Trusting, in other words, simplifies life for individual consumers in a developing country.

This pattern of relationships suggests that when thinking about one's attitude toward changes in marketing in the last five years, the poor think of their trust for market-related institutions and then business' contributions to their QOL. The thought process for the nonpoor differs from that of the poor. When thinking about one's attitude toward changes in marketing in the last five years, the non-poor think of their attitude toward marketing and then business' contributions to their QOL. All of this suggests that the poor in a developing country value the protection offered by market-related institutions, while the non-poor prize the benefits offered by market-related institutions.

In terms of perceptions about the marketplace, results suggest that the poor are more mindful of the maleficence that can occur in market transactions. Although poor consumers in this study did not necessarily live under conditions of abject poverty, the finding that consumers who fall below the poverty line emphasize maleficent aspects of the market is consistent with the psychological experience of subsistence consumers living in conditions of abject poverty (Viswanathan and Rosa, 2007), as illustrated by the moderatelysized relationship in the second step of the three-step model where CTMRI influences BCM-QOL (Fig. 3). Externalities and internalities both may contribute to such a relationship. By comparison, the nonpoor appear to be more mindful of the beneficence of the marketplace, as illustrated by the strong relationship in the second step of the three-step model where CATM influences BCM-QOL (Fig. 4).

\subsection{Contributions and implications}

This study incorporated an exogenous measure of five-year changes in marketing. By doing so, researchers tested a causal model of how marketing management practices influence quality-of-life perceptions. This extends past quality-of-life research grounded in correlational models. Causal models provide insight into processes behind social phenomena (Peterson and Ekici, 2007; Ekici and Peterson, 2009). While past studies demonstrated robust associations between trust and quality-of-life, the present findings illustrate how these attitudes are formed in a three-step process grounded in perceptions of marketing management practices. Highlighting this process illuminates the influence, from the perspective of poor consumers, that formal market mechanisms aimed at alleviating poverty can exert.

The causal model also supports the idea that, in forming quality-oflife attitudes, poor consumers in developing countries form attitudes about the marketplace that are similar to attitudes exhibited among subsistence consumers (Viswanathan and Rosa, 2007). Although poor consumers in this study did not live in conditions of abject poverty, they emphasized avoiding the harmful aspects of the marketplace in assessments of how marketing practices influence their quality-of-life. Poor consumers did not place importance on the potential benefits of the market in the assessment of their quality-of-life. This is consistent with the idea that many subsistence consumers resolve themselves to the idea of living in abject poverty; and despite not necessarily living in conditions of abject poverty, those living below the poverty line in this study did not see the formal marketplace as offering them opportunity to improve their condition.

Finally, the causal model of this study provides a more accurate reflection than correlational models of the influence of marketing practices on perceptions of business' contribution to quality-of-life. The findings suggest that consumers living below the poverty line in a developing country differ in how they perceive business contributes to their quality-of-life from consumers living above the poverty line. This is consistent with the notion that heterogeneity in consumer needs and perceptions marks even poor populations (Kotler et al., 2006). By illuminating a process by which poor consumers develop quality-of-life attitudes, this study provides insight into how to potentially structure segmentation strategies in developing countries to better understand the needs of poor consumers. For example, valuable insights would likely emerge from segmenting poor consumers into groups representing those with higher marketplace trust and those with lower marketplace trust, conducting analyses and then comparing results across these two groups.

Camfield (2006) asserts that a complete picture of well-being for individuals would include measures of one's state of body (material endowments, such as income) as well as state of mind (subjective perceptions that would include inter-subjective perceptions about social interactions and what people value). This study included measures of objective endowments (income), as well as the subjective (QOL measures). Importantly, this study included the inter-subjective (CTMRI representing what consumers trust about market-related institutions and CATM representing consumer judgments about marketing practices in the marketplace). In this way, the study presents a more complete picture of well-being for consumers in a developing country.

The results of the study reflect a lower average QOL rating compared to the non-poor, as well as a pronounced mindfulness of the non-maleficence of markets. Researchers have previously noted that the nature and extent (or lack thereof) of respectful and trusting ties to representatives of formal institutions have a major influence on the welfare of individuals - especially for those in poor communities (Szretzer and Woolcock, 2004). Based on the findings, developingcountry policy makers would do well to focus on building, and strengthening trust with citizens. Promising first steps include boosting institutional transparency and increasing the provision of information about market-related institutions. Perhaps, people can only trust what they know, suggesting that richer knowledge about market-related institutions might enhance trust and likely diminish the poor's heightened focus on maleficent aspects of markets.

The beneficence/non-maleficence perspective on the marketplace also offers developing-country policy makers with possible answers. From the institutional theory perspective, the institutions' (or its agents') actions and performances should affect trust in market-related 
institutions. Authors in various disciplines have suggested that, from the perspective of the trustee (market-related institutions in this case), fulfilling fiduciary obligations (e.g. Barber, 1983), being benevolent (e.g. Doney and Cannon, 1997), and being thoroughly accountable (e.g. Hardin, 1991) can enhance trustworthiness. As a result, encouraging the public's direct participation during the policy-making process, and communicating the results of policy-enforcement action with the public (in the form of product recall, bans, and so forth) may enhance public trust for governmental agencies.

\subsection{Generalizability}

This study focused upon fundamental concepts and processes consumers use in thinking about markets. As such, the results provide insight into other developing countries recovering from economic crisis. This study illustrates the similarities across poor and non-poor consumers in their pattern of thinking about the effects of changes in marketing practices. Because many developed economies have been immune to economic crises, this study focused on the poor in developing countries recovering from such crises. However, the global economic crisis that began in 2008 has introduced similar circumstances of economic hardship to all corners of the world. Researchers can now begin to hypothesize about how the poor in developed countries will think about changes in marketing five years after the current economic crisis. Because this study used sound methodological approaches and rigorous analytical techniques, one can expect to find similarities in the way the poor think about marketing and their quality-of-life five years after the current global economic crisis subsides. Other researchers have noted how the poor in developed countries perceive the market as a more hostile place (with limited product availability and higher prices for goods and services in economically poor neighborhoods) than do the non-poor of developed countries (Hill and Stephens, 1997).

Additionally, the increased generalizability of this study's results to countries that share geographic, historical, and cultural ties and roots to Turkey (such as the Balkan, Middle Eastern, Northern African, Asian, and former Soviet Union countries with Turkic populations, namely Georgia, Armenia, Azerbaijan, Turkmenistan, Kazakhstan, Tajikistan, and Kyrgyzstan). All of these countries can benefit from this study as many of them have just begun pursuit of a free-market economy in which Turkey has participated for decades.

\section{Future research}

The authors of this study recommend two phases of research to build upon this study's findings. In phase one, the authors recommend going beyond an economic definition of poverty and initiating a secondary research and qualitative research effort to develop a typology of the poor in Turkey. Future studies can pursue a typology based on 1) endogenous outcomes (being classified in the underclass, in the working poor, or in the transiently poor), 2) exogenous factors (living in a geographic area, being born into a group with an ethnic/ political orientation outside of the cultural mainstream, or being afflicted with poor health or a personal handicap), or 3) a mix of these (migrating, choosing to become a member of an outlawed political party, or adopting unhealthy lifestyles based on substance abuse).

In phase two, the authors recommend conducting a large-scale nationally-representative sampling effort that would include the major sub-groups of the poor identified in phase one. This sampling approach would boost the effectiveness of the conduct of a survey focused on consumer perceptions about markets (CTMRI), about marketing (CATM) and about QOL. This survey will allow researchers to make comparisons across the sub-groups among the poor identified in the first phase of research. The survey should also allow researchers to make comparisons with those above the poverty line. In these ways, future research can build on the knowledge gained in this study about the different way the poor view markets.

\section{References}

Ajzen I. Consumer attitudes and behavior. In: Haugtvedt C, Herr P, Kardes F, editors. Handbook of consumer psychology. New York, NY: Psychology Press; 2008. p. 525-48.

Baker S, Gentry J, Rittenburg T. Building understanding of the domain of consumer vulnerability. J Macromark 2006;25(2):128-39.

Barber B. The logic and limits of trust. New Brunswick, NJ: Rutgers University Press; 1983.

Baker S, Hunt D, Rittenberg T. Consumer vulnerability as a shared experience: tornado recovery process in Wright Wyoming. J Public Policy Mark 2007;26(1):6-19.

Becker G. Disrupted lives: how people create meaning in a chaotic world. Berkeley: University of California Press; 1997.

Bentler PM. Comparative fit indexes in structural models. Psychol Bull 1990;107:238-46.

Bollen KA. Structural equations with latent variables. New York, N.Y.: John Wiley and Sons; 1989

Bugra A, Keyder C. New poverty and the changing welfare regime of Turkey. Ankara: United Nations Development Program; 2003.

Burroughs J, Rindfleisch A. Materialism and well-being: a conflicting values perspective. J Consum Res 2002(29):348-70 December.

Camfield L. The why and how of understanding 'subjective' wellbeing: exploratory work by the WeD Group in four developing countries. ESRC Research Group on Wellbeing in Developing Countries: WeD Working Paper 26; 2006.

Diener E, Emmons R, Larsen R, Griffin S. The satisfaction with life scale. J Pers Assess 1985;49(1):71-5.

Diener Ed, Suh EunkookM, Lucas RichardE, Smith HeidiL. Subjective well-being: three decades of progress. Psychol Bull 1999;125(2):276-302.

Doney PM, Cannon JP. An examination of the nature of trust in buyer-seller relationships. J Mark 1997;61(2):35-51.

Douglas SP, Craig SC. On improving the conceptual foundations of international marketing research. J. Int. Mark. 2006;14(1):1-22.

Du Toit A. Poverty measurement blues: some reflections on the space for understanding 'chronic' and 'structural' poverty in South Africa. Paper prepared for the First International Congress on Qualitative Inquiry, University of Illinois at Urbana-Champaign, 5-7 May; 2005.

Eagly A, Chaiken S. The psychology of attitudes. New York: Thomson; 1993.

Earle T, Cvetkovich G. Social trust: toward a cosmopolitan society. Westport, CT: Praeger; 1995.

Ekici A, Peterson M. The unique relationship between quality-of-life and consumer trust for market-related institutions among financially-constrained consumers in a developing country. J Public Policy Mark 2009;28(1):56-70.

Fishbein M, Ajzen I. Belief, attitude, intention, and behavior: an introduction to theory and research. Reading, MA: Addison-Wesley; 1975.

Fligstein Neil, Dauter Luke. The sociology of markets. Annu Rev Sociology 2007;33:105-28.

Gaski JF, Etzel MJ. The index of consumer sentiment toward marketing. J Mark 1986;50:71-81 July.

Gerbing DW, Anderson JC. An updated paradigm for scale development incorporating unidimensionality and its assessment. J Mark Res 1988;25:186-92 May.

Grossbart S, Hollander S, Falkenberg A. From the Editors. J Macromark 2001;21(3):3-5.

Grossbart S, Hollander S, Falkenberg A. From the editors. J Macromark 2002;21(1):3-5.

Güvenç M, Şenyapılı T. İstanbul emek pazarında 2001 krizinin toplumsal sonuçları: Krize direnis biçimleri. Görüs 2003:44-8 Temmuz.

Hair Jr JF, Anderson RE, Tatham RL. Multivariate data analysis. New York, NY: MacMillan; 1991.

Hardin R. The artificial duties of contemporary professionals. Soc Serv Rev 1991;64:528-41 December.

Harris R, Carman J. Public regulation of marketing activity, part I: institutional typologies of market failure. J Macromark 1983;3:49-58 Spring.

Hill R, Stephens D. Impoverished consumers and consumer behavior: the case of AFDC mother. J Macromark 1997;17:32-48 (Fall).

Kotler P, Roberto N, Leisner T. Alleviating poverty: a macro/micro marketing perspective. J Macromark 2006;26(2):233-9.

Larsen R, Eid M. Ed Diener and the science of subjective well-being. In: Eid M, Larsen R, editors. The science of subjective well-being; 2008. p. 1-16.

Lee DJ, Sirgy MJ, Larsen V, Wright ND. Developing a subjective measure of consumer well-being. J Macromark 2002;22(2):158-69.

Lee DJ, Sirgy MJ. Quality-of-life (qol) marketing: proposed antecedents and consequences. J Macromark 2004;24(1):44-58.

Leicht J. Political and social dimensions of the Turkish financial crisis; 2001. available at www.wsws.org/articles/2001/mar2001/turk-m07.shtml, date of access: Feb 1st, 2009.

Malhotra N. Basic marketing research. Upper Saddle River, NJ: Prentice Hall; 2009.

Mittelstaedt J, Kilbourne W, Mittelstaedt R. Macromarketing as agorology: macromarketing theory and the study of the agora. J Macromark 2006;26:131-42 December.

Nason R. The social consequences of marketing: macromarketing and public policy. J Public Policy Mark 1989;8:242-51.

New Anatolian. Turkey Hunger Line at YTL 573, Poverty Line at YTL 1, 867, 2006.

Peterson M, Ekici A. Consumer attitude toward marketing and subjective quality-of-life in the context of a developing country. J Macromark 2007;27(4):350-9.

Petkoski DjordjijaB, Rangan VKasturi, Laufer WilliamS. Business and poverty: opening markets to the poor. Dev Outreach 2008:10(2):2-6.

Sen Amartya. Development as freedom. New York: Anchor Books; 1999.

Sirgy MJ. Handbook of quality-of-life research. Boston: Kluwer; 2001.

Szretzer S, Woolcock M. Health by association? Social capital, social theory, and the political economy of public health. Int J Epidemiol 2004;33(4):650-67. 
Sztompka P. Trust: a sociological theory. Cambridge University Press; 1999.

Varadarajan PR, Thirunarayana PN. Consumers' attitudes towards marketing practices, consumerism, and government regulations: cross-national perspectives. Eur J Mark 1990;24(6):6-23.

Viswanathan M, Rosa JA. Product and market development for subsistence marketplaces: consumption and entrepreneurship beyond literacy and resource barriers. Adv Int Manag 2007;20:1-17.

Viswanathan M, Rosa JA, Sridharan S, Gau R, Ritchie R. Designing marketplace literacy education in resource-constrained contexts: implications for public policy and marketing. J Public Policy Mark 2009;28(1):85-94.
White J. Turkey's poverty line August 28; 2008. http://www.kamilpasha.com/2008/08/ 28/turkeys-pverty-line/.

Wilkie W. The world of marketing thought: where are we heading? In: Sheth JN, Sisodia RS, editors. Does marketing need reform?: fresh perspectives on the future. Armonk, NY: M. E. Sharpe; 2006. p. 239-47.

Yeldan AE. Turkey and the long decade with the IMF: 1998-2008; 2008. available at www networkideas.org/news/jun2008/Turkey_IMF.pdf, date of access: Feb 1st, 2009.

Zabci F. A poverty alleviation programme in Turkey: the social risk mitigation project. South East Eur Rev Labour Soc Aff 2006;1:109-25. 